\title{
A One-Pot Procedure for The Synthesis of Aromatic Aldehydes in a Heterogeneous Medium
}

\author{
GEORGE BRATULESCU* \\ University of Craiova, Faculty of Sciences, Department of Chemistry, 13 A. I. Cuza Str., 200585, Craiova, Romania

\begin{abstract}
Aromatic aldehydes were obtained from halogenated compounds and DMSO in solvent free medium. The method involves a Kornblum's oxydation of organic halide in mild conditions using microwaves. An inorganic base such as solid potassium bicarbonate is used. The procedure is a smooth alternative to obtain aromatic aldehydes in heterogeneous medium. The important benefits of the method are also the absence of
\end{abstract} \\ catalysts, the low time, and the good yield of the synthesis.
}

Keywords: aromatic aldehydes, DMSO, organic halides, Kornblum's reaction, microwaves

An important class of compounds in organic chemistry are aromatic aldehydes. They play an important role as intermediates in fine organic synthesis and in the pharmaceutical industry as well [1,2]. Many aromatic aldehydes are found in essential oils, causing characteristic smell [3].

Some aromatic aldehydes are important components employed in the cosmetics industry as additives in perfumes, dyes, and may also acts as a bee repellant $[4,5]$. As denaturants, aromatic aldehydes by their bitter flavor make the products inappropriate for oral consumption [4].

Due to the importance of aromatic aldehydes, many synthetic methods have been developed over time to obtain them [6]. Thus, we can mention the Rosenmund's reaction of acid chlorides [7], Étard reaction [8, 9], the reaction of Casiraghi [10], Gattermann-Koch reaction, Duff's hexamethylenetetramine reaction, Reimer-Tiemann reaction, Vilsmeier-Haack reaction [11] and so on [12, 13]. More than that, oxidation of methylarenes [14] and benzylic alcohols [15] have also been implemented as methods of synthesis of aromatic aldehydes.

Oxidation of primary halides with dimethylsulfoxide known as Kornblum oxidation allows to obtain the aromatic aldehydes, too $[16,17]$. The conventional approach to Kornblum oxidation requires hazardous solvents as a reaction medium such as $\mathrm{MeCN}, \mathrm{DMF}, \mathrm{CHCl}_{3}$, a tertiary amine catalyst, and a very long reaction time to get the aromatic aldehyde [18, 19]. Disadvantages like rigorous reaction conditions, low yield, tedious protocols are limiting factors for using these procedures.

\section{Experimental part}

Reagents, equipment and methods

Arylmethy bromide, potassium bicarbonate and DMSO are commercially substances. The obtained compounds were identified by TLC (silica gel, $\mathrm{Et}_{2} \mathrm{O}$ ), elemental analysis and IR spectra. The melting points were measured on a Gallenkamp digital melting point apparatus. Boiling points were measured by distillation. IR/ FT spectra were recorded with an Bruker ALPHA FTIR spectrometer. A Rohnson microwave device operating at $320 \mathrm{~W}$ was employed. The mass spectrum of 4-(N,N-dimethylamino) benzaldehyde was obtained by electron impact using a Nermarg R10-10 spectrometer.

\section{General procedure of synthesis}

Into a $25 \mathrm{~mL}$ Erlenmeyer beaker is placed $6 \mathrm{mmol}$ of DMSO, $4.5 \mathrm{mmol}$ of arylmethyl bromide, and $10.5 \mathrm{mmol}$ of potassium bicarbonate. The mixture was irradiated with microwaves according to the time required. The resulting mixture was poured into $75 \mathrm{~mL}$ of ice-water and extracted twice with $75 \mathrm{~mL}$ of ether. Evaporation of the solvent leads to the product of high chemical purity (table 1). The boiling points or melting points of the aromatic aldehydes correspond to the literature data of the known compounds.

\section{Results and discussions}

Previously [20, 21], we synthesized some organic compounds in the paste medium. Dimethyl sulfoxide and arylmethyl bromides are strong polar molecules and absorb very well the microwaves. Following this behavior,

\footnotetext{
*email: georgebratulescu@yahoo.com
} 
Kornblum reaction of aromatic aldehydes synthesis becomes possible under microwaves. All reagents were well mixed in a beaker. In the resulting heterogeneous medium during the irradiation period hot spots are created. They are similar to catalytic centers and allow the reaction to proceed rapidly [21].

The irradiation time was 2-4 minutes, then the product was extracted with diethyl ether. Evaporation of the extraction solvent leads to aromatic aldehyde (table 1).

The Kornblum oxidation reaction takes place on the surface of the potassium bicarbonate granules. The resulting transition state of lower energy increases the reaction velocity of arylmethyl bromide oxidation. The reaction mechanism was previously depicted and is shown below [22]:

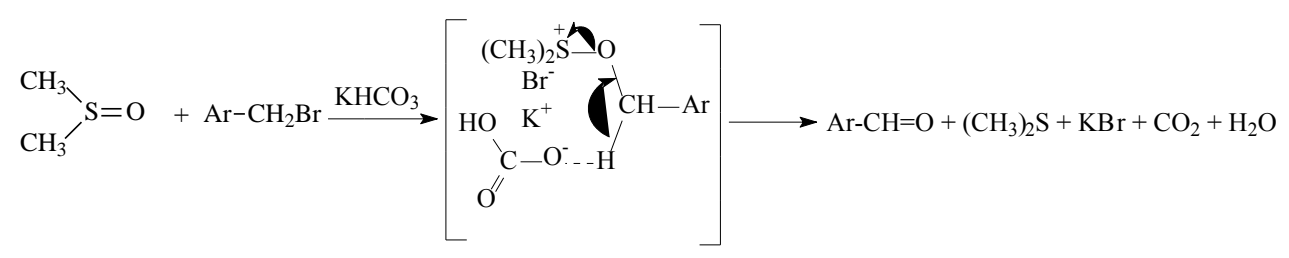

Table 1

AROMATIC ALDEHYDES, ArCHO, SYNTHESIZED BY KORNBLUM OXIDATION USING MICROWAVES

\begin{tabular}{|c|c|c|c|c|c|}
\hline${ }_{\circ} \mathrm{N}$ & $\mathrm{ArCHO}$ & $\begin{array}{l}\text { Time } \\
(\mathrm{min}\end{array}$ & $\begin{array}{l}\text { Yield } \\
(\%)\end{array}$ & $\begin{array}{c}\mathrm{IR} \\
\tilde{\mathrm{v}}\left[\mathrm{cm}^{-1}\right] \\
\mathrm{CH}=\mathrm{O}\end{array}$ & $\begin{array}{c}\text { Bp } \\
\left({ }^{\circ} \mathrm{C}\right) / \text { Torr }\end{array}$ \\
\hline 1 & $\mathrm{PhCHO}$ & 3 & 94 & $1701 \mathrm{vs}$ & $178-180 / 760[23]$ \\
\hline 2 & 2- $\mathrm{BrC}_{6} \mathrm{H}_{4} \mathrm{CHO}$ & 3.5 & 80 & 1699 vs & $228-230 / 760[24]$ \\
\hline 3 & $3-\mathrm{BrC}_{6} \mathrm{H}_{4} \mathrm{CHO}$ & 4 & 87 & 1702 vs & $227.5-230^{\mathrm{a}}[25]$ \\
\hline 4 & $4-\mathrm{BrC}_{6} \mathrm{H}_{4} \mathrm{CHO}$ & 4 & 84 & 1696 vs & $57-58^{\mathrm{a}}[26]$ \\
\hline 5 & $2-\mathrm{EtC}_{6} \mathrm{H}_{4} \mathrm{CHO}$ & 4 & 81 & $1699 \mathrm{~s}$ & $210-213 / 760$ [27] \\
\hline 6 & 3 - $\mathrm{EtC}_{6} \mathrm{H}_{4} \mathrm{CHO}$ & 3 & 84 & $1700 \mathrm{~s}$ & $214 / 760[28]$ \\
\hline 7 & $4-\mathrm{EtC}_{6} \mathrm{H}_{4} \mathrm{CHO}$ & 3.5 & 86 & 1702 vs & $108-110 /[29]$ \\
\hline 8 & $2-\mathrm{iPrC}_{6} \mathrm{H}_{4} \mathrm{CHO}$ & 4 & 70 & 1698 vs & $74-75 / 5[30]$ \\
\hline 9 & $3-\mathrm{iPrC}_{6} \mathrm{H}_{4} \mathrm{CHO}$ & 4 & 75 & $1700 \mathrm{~s}$ & $216.6 / 760[31]$ \\
\hline $0^{1}$ & 4-iPrC $\mathrm{P}_{6} \mathrm{H}_{4} \mathrm{CHO}$ & 3.5 & 77 & $1701 \mathrm{vs}$ & $235 / 760[32]$ \\
\hline 1 & $2-\mathrm{O}_{2} \mathrm{NC}_{6} \mathrm{H}_{4} \mathrm{CHO}$ & 2 & 93 & $1694 \mathrm{vs}$ & $44-45 / 760$ [33] \\
\hline $2^{1}$ & $\mathrm{p}-\left(\mathrm{CH}_{3}\right)_{2} \mathrm{NC}_{6} \mathrm{H}_{4} \mathrm{CHO}$ & 4 & 87 & $1683 \mathrm{~s}$ & $70-73^{\mathrm{a}}[34]$ \\
\hline
\end{tabular}

The electron impact mass spectrum of 4-(N,N-dimethylamino) benzaldehyde was studied (fig. 1$)$ and shows the presence of the molecular ion peak at $\mathrm{m} / \mathrm{z} 149$. This peak is assigned to the unfragmented radical cation $\mathrm{M}^{+}$and it is also called the parent's peak or the molecular ion [16]. A very low satellite peak $(\mathrm{M}+1)$ at $\mathrm{m} / \mathrm{z} 150$, near the parent ion peak, is due to the isotopic distribution of the elements in 4-(N,N-dimethylamino) benzaldehyde. The molecular ion peak and the base peak are different. The base beak (tallest peak, $\mathrm{I} \%=100$ ) was identified at $\mathrm{m} / \mathrm{z} 148$ and corresponds to (4-(dimethylamino)phenyl)(oxo)methylium cation. Three fragmentation pathways in electron impact mass spectra of 4-(N,N-dimethylamino)benzaldehyde stand out $(\mathbf{A}, \mathbf{B}, \mathbf{C}$, scheme 1$)$.

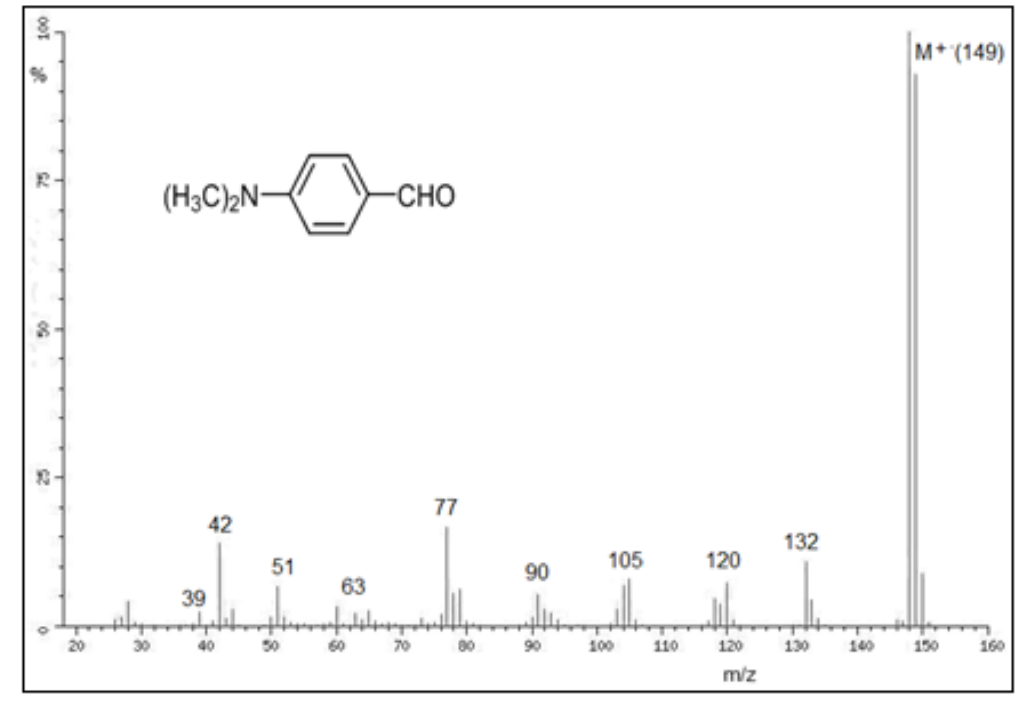

Fig. 1. Electron impact mass spectrum of $4-(N, N-$ dimethylamino)benzaldehyde 
In the first fragmentation pathway (A), the molecular radical cation $\mathrm{M}^{+\cdot}$ of $p$-(N,N-dimethylamino) benzaldehyde loses a hydrogen atom of the formyl group and forms the radical cation of (4-(dimethylamino)phenyl)(oxo)methylium $(\mathrm{m} / \mathrm{z}$ 148). Then, the leakage of a carbon monoxide molecule produces the (dimethylamino) phenyl radical cation $(\mathrm{m} / \mathrm{z}$ 120). An ethane elimination by an unimolecular decomposition reaction, generates the radical cation of nitrene $(\mathrm{m} / \mathrm{z}$ 90), which isomerizes to 7-azabicyclo[4.1.0]hepta-1(6),2,4-triene-7-yl cation, and then, by a loss of hydrogen cyanide, gives ethynylcyclopropenylium cation ( $\mathrm{m} / \mathrm{z}$ 63) [36]. Removal of benzene from the (dimethylamino) phenyl cation leads to aziridinyl cation $(\mathrm{m} / \mathrm{z} 42)$.

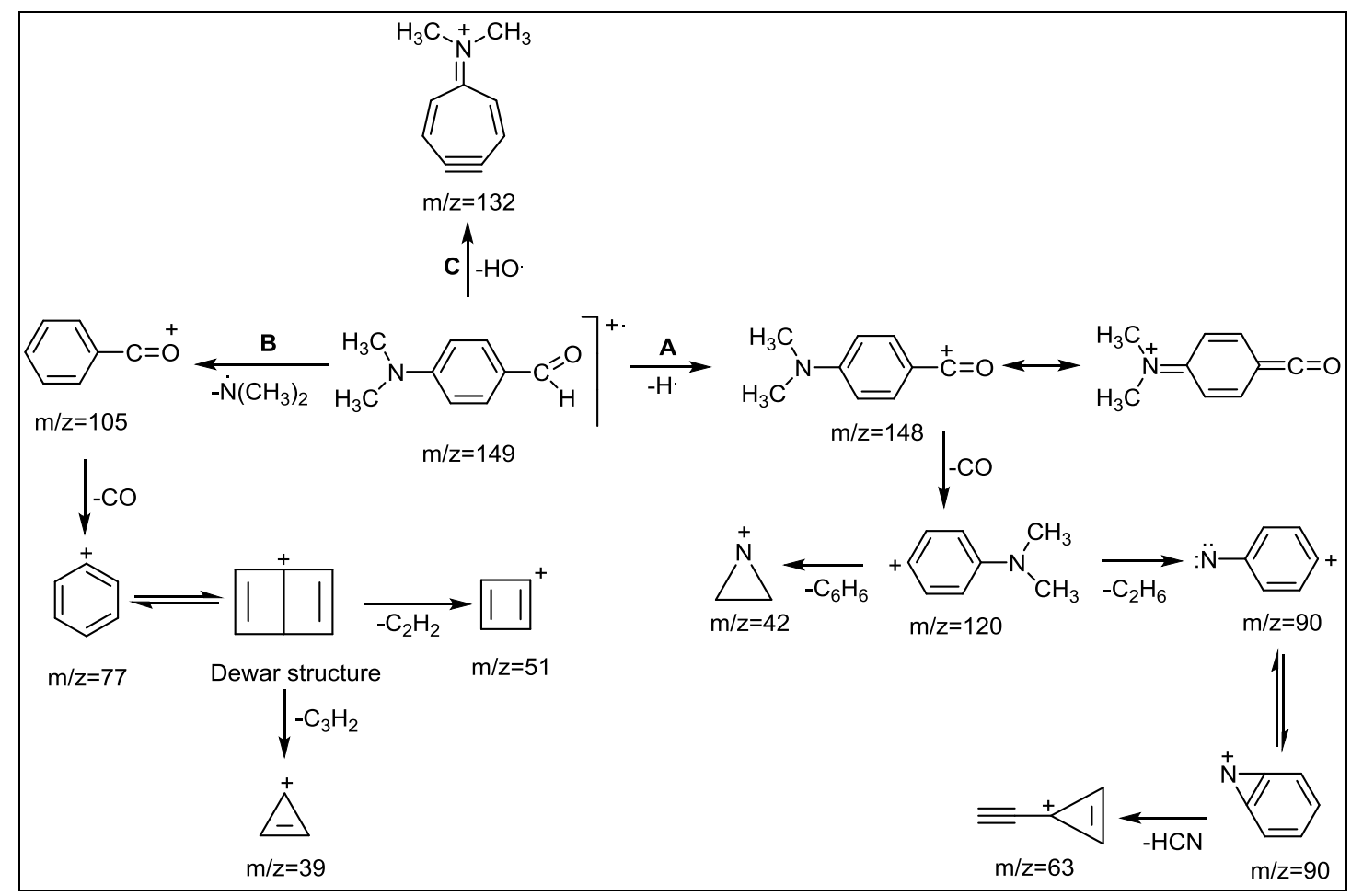

Scheme 1. Fragmentation mechanism of 4-( $N, N$-dimethylamino) benzaldehyde

In the second fragmentation pathway (B), the molecular ion $\mathrm{M}^{+} \cdot$ of $p$ - (N,N-dimethylamino) benzaldehyde, by an $\alpha$ cleavage of the covalent bond, releases a dimethylamino radical to form the stable benzoyl cation $(\mathrm{m} / \mathrm{z} 105)$ according to Stevenson's rule. Furthermore, the latter losses a molecule of carbon monoxide and forms the phenyl cation $(\mathrm{m} / \mathrm{z}$ 77). This radical cation is a high-energy, unstable specie and releases an acetylene molecule from the Dewar valence isomer structure to give an antiaromatic cyclobutadiene cation $(\mathrm{m} / \mathrm{z} 51)$. The loss of cyclopropenylidene, or 3-carbon ring carbene, $\mathrm{C}_{3} \mathrm{H}_{2}$, leads to the aromatic cyclopropenyl cation $(\mathrm{m} / \mathrm{z} 39)$.

The third fragmentation pathway (C) leads to the charge-delocalized cation of N-(cyclohepta-2,6-dien-4-yn-1ylidene)-N-methylmethanaminium $(\mathrm{m} / \mathrm{z}$ 132) by hydroxyl radical cleavage from the molecular ion. Having an electronic structure in which the positive charge can be delocalized to eight atoms, this cation has an important relative abundance in the mass spectrum of the compound. In any case, this cation at $\mathrm{m} / \mathrm{z} 132$ (pathway $\mathbf{C}$ ) is more stable than the cation at $\mathrm{m} / \mathrm{z} 90$ (pathway $\mathbf{A}$ ) as it results from the height of their peaks.

\section{Conclusions}

Aromatic aldehydes can be obtained from arylmethyl bromides by an easy protocol. The Kornblum oxidation carried out with DMSO in the presence of potassium bicarbonate in a heterogeneous medium occurs within a few minutes. The removal of the compounds from the reaction medium is not difficult and the yield of the synthesis is high. Last but not least, using microwaves, energy consumption is much lower than conventional approach.

\section{References}

1. STEPHANE, C., ROBERT, W. D., SALly, G. R., JOHN, A. R., DAVID, H. B. R., Chem. Rev., 106, no. 7, 2006 , p. 2943.

2. ACKERMANN, L., Chem. Commun., 46, no.27, 2010, p. 4866.

3. BRENES, M., GARCIA, A., GARCIA; P., RIOS, J. J., GARRIDO, A., J. Agric. Food. Chem., 47, no.9, 1999, p.3535.

4. ANDERSEN, A., Int. J. Toxicol., 25, no.1, 2006, p. 11.

5. VERMA, R. S., PADALIA, R. C., SINGH, V. R., GOSWAMI, P., CHAUHAN, A., BHUKYA, B., Int J Food Prop., 20, no.2, 2017, p. 1259.

6. KANTLEHNER, W., Eur. J. Org. Chem., 14, 2003, p. 2530.

7. ROSENMUND, K. W., Chem. Ber., 51, no.1, 1918, p. 585. 
8. HARTFORD, W. H., DARRIN, M., Chem. Rev., 58, no.1, 1958, p. 1.

9. RENTEA, C.N., RENTEA, M., NECSOIU, I., NENITZESCU C.D., Tetrahedron, 24, no.13, 1968, p. 4667.

10. HOFSLOKKEN, N. U., SKATTEBOL, L., Acta Chem. Scand., 53, 1999, p. 258.

11. FERGUSON. L. N., Chem. Rev., 38, no.4, 1946, p. 227.

12. KANTLEHNER, W., Eur. J. Org. Chem., 3, no.14, 2003, p. 2530.

13. GAZIZOV, M. B., IVANOVA, S. Y. U., IBRAGIMOV, S. N., BAGAUVA, L. R., KHAIRULLIN, R. A., MEDVEDEVA, K. A., Russ. J,

Gen. Chem., 86, 2016, no.9, p. 2129.

14. FENG, J. B., WU, X. F., Appl. Organomet. Chem., 29, no.4, 2015, p. 63-86.

15. MALLAT, T., BAIKER, A., Chem. Rev., 104, no.6, 2004, p. 3037.

16. KORNBLUM, N., POWERS, J. W., ANDERSON, G. J., JONES, W .J., LARSON, H. O., LEVAND, O., WEAVER, W. M., J. Am. Chem.

Soc., 79, no.24, 1957, p. 6562 .

17. KORNBLUM, N., POWERS, J. W., ANDERSON, G. J., J. Am. Chem. Soc., 81, no.15, 1959, p. 4113.

18. TIDWELL, T. T., Org. React., 39, 1990, p. 297.

19. WU, X. F., Sci. Rep., 8, 2018, no.1, p. 8389.

20. BRATULESCU, G., Tetrahedron Lett., 79, no.6, 2008, p. 984.

21. BRATULESCU, G., Curr. Org. Synth., 10, no.6, 2013, p. 947.

22. BRATULESCU, G., Synth. Commun., 38, 2008, no.16, p. 2748.

23. MEYERS, C. Y., J. Org. Chem., 26, no. 3, 1961, p. 1046.

24. CHO, C. S., JIANG, L. H., SHIM, S. C., Synth. Commun., 28, no.5, 1998, p.849.

25. LAKOURAJ, M. M., TAJBAKHSH, M., SHRINI, F., ASADY, T. M., Phosphorus Sulfur Silicon Relat. Elem., 180, 2005 , no.6, p.2423.

26. HAJIPOUR, A. R., ZAHMATKESH, Z., RUOHO, A. E., Synthetic Commun., 36, no.1, 2006, p.71.

27. JONES, G., J. Chem. Soc., 1960, p.1918.

28. BODEN,N., FEENEY, J., SUTCLIFFE, L. H., J. Chem. Soc., 1965, p. 3482.

29. OHNO, M., INOUYE, Y., HATANAKA, A., KAZIWARA, T., Bull. Inst. Chem. Res., Kyoto univ, 43, 1965, p. 231.

30. ABE, S., YASUKAWA, T., Nippon Kagaku Zasshi, 86, 1965, p.433.

31. PANDEY, G., SINGH, R. P., GARG, A., SINGH, V. K., Tetrahedron Lett., 46, no.12, 2005, p. 2137.

32. BASLAS, K. K., DESHPANDEY, S. S., J. Indian Chem. Soc., 28, 1951, p. 19.

33. BABU, M. S., RAI, K. M. L., Tetrahedron. Lett., 45, no. 42, 2004, p. 7969.

34. GHOLAMHASSAN, K. I., MOHAMMAD, R. Z., HABIBOLLAH, E., KEYVAN, S., J. Chem. Res., 3, 2006, no.3, p. 151.

35. BRATULESCU, G., Introducere în spectroscopia compuşilor organici (in Romanian), Ed. Sitech, Craiova, 2008 , p.92.

36. WEINER, B., WILLIAMS, C. J., HEANEY, D., J. Phys. Chem., 94, no.18, 1990, 18, p.7001.

Manuscript received: 11.02 .2019 